\title{
In memoriam Andreas Emilio Beck
}

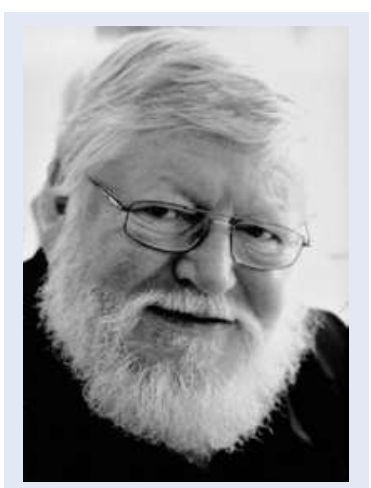

Dr. med. Andreas Beck (26.12.1936-15.11.2012)
Aus einer Juristenfamilie stammend, besuchte Andreas Beck das Gymnasium in Bern, absolvierte dort sein Medizinstudium und schloss 1966 mit dem Staatsexamen ab. Kurz danach gründete er eine Familie, aus der drei Kinder stammen. Er bildete sich zielstrebig an ver schiedenen Spitälern in der Schweiz weiter und erwarb den Facharzttitel in Chirurgie. 1972 wurde er zum Chefarzt-Stellvertreter an der chirurgischen Abteilung des damaligen Bezirksspitales Grosshöchstetten nominiert. 1978 promovierte er über Orthopädische Chirurgie und eröffnete seine Privatpraxis in Bern. Als Leitender Arzt war er an der chirurgischen Abteilung der Klinik Beau-Site operativ tätig.

Andreas Beck setzte sich mit grossem Engagement auch für den Sanitätsdienst ein. 1989 wurde er zum Oberst befördert und hatte während vier Jahren das Amt eines Territorialarztes inne.

Glückliche Umstände und sein Freund Dr. med. Hannes Hodel führten zur Begegnung mit der noch unbekannten Neuraltherapie, die ihn faszinierte und $\mathrm{zu}$ seinem Lebensinhalt wurde. Er erlebte, dass mit Neuraltherapie die Chirurgie oft überflüssig war, und er widmete sich uneingeschränkt dieser neuen Disziplin mit ihren unkonventionellen Denkansätzen.

Animiert von seinen Lehrern und Freunden Franz Hopfer, Otto Bergsmann und Peter Dosch widmete er immer mehr Zeit für die Ausbildung junger Kollegen in Neuraltherapie. In unzähligen Kursen hat er sich für die Anliegen und die fortschrittliche Behandlungsart nach Huneke eingesetzt. Als Organisator und Leiter führte er 15 Wochenkurse in Sils Maria durch, hielt Vorträge an Kongressen im In- und Ausland (u.a. in Los Angeles und Cambridge) bestritt Präsentationen bei Krankenkassen und Versicherungen und auch vor Laienpublikum. Mit Publikationen sorgte er für die Verbreitung der Neuraltherapie. Dabei scheute er auch die oft skeptischen Fragen der Presse nicht und argumentierte hier mit klugem, manchmal bissigem Scharfsinn.

1986 gründete er die Schweizerische Gesellschaft für Neuraltherapie (Regulationstherapie) nach Huneke, die er über 23 Jahre präsidierte und zu deren Ehrenpräsidenten er im Jahre 2009 ernannt wurde.

Zusammen mit Ex-Nationalrat Hafner führte er die Volksinitiative zur Schaffung eines Lehrstuhles für Komplementärmedizin an der Medizinischen Fakultät der Universität Bern durch. Nach Annahme der Kampagne entstand 1995 an der Universität Bern das weltweit erste Ordinariat für Komplementärmedizin: KIKOM (Kollegiale Instanz für Komplementärmedizin). Von den vier komplementärmedizinischen Fachgebieten führte Andreas Beck während sechs Jahren die Dozentur für Neuraltherapie und wurde Ende 2001 altershalber emeritiert. Neben der Neuraltherapie setzte er sich standespolitisch für die Akzeptanz der Komplementärmedizin ein. Er war Gründungsmitglied der SAGEM (Schweiz. Ärztegesellschaft f. Erfahrungsmedizin) und stand ihr von 1995 bis 2002 als Präsident vor. Als Mitbegründer der UNION (Union schweizerischer komplementärmedizinischer Ärztegesellschaften), als Mitglied der ELK (Eidg. Leistungskommission) und ab 1989 als Vizepräsident des ECPM (European council of doctors for plurality in medicine) in Brüssel hat er seine Aktivitäten unentwegt entfaltet. Im Initiativkomitee zur Volksinitiative «Ja zur Komplementärmedizin» setzte er sich als Delegierter ein und kämpfte unermüdlich.

All seine Bemühungen hatten schliesslich zur Folge, dass die Neuraltherapie durch die FMH anerkannt wurde und seither die Zusatzbezeichnung «Neuraltherapeut» geführt werden kann. Beck wird als kämpferischer Arzt in die Medizingeschichte eingehen; es ist sein Verdienst, dass die Neuraltherapie in der Schweiz bekannt und allgemein akzeptiert ist.

«Er war ein Vorkämpfer für die Neuraltherapie und für die Komplementärmedizin», sagt die Dakomed (Dachverband für Komplementärmedizin). «Sein politisches Engagement hat im Kanton Bern zu einem Verfassungsartikel und zur Schaffung der KIKOM geführt. Er hat vermutlich damit einen wichtigen Samen gestreut und das Fundament erschaffen, damit ein nationaler Verfassungsartikel möglich wurde. Danke.»

Für seine Verdienste um die Komplementärmedizin wurden ihm etliche Ehrungen zuteil, so durfte er 1993 die Huneke-Medaille entgegennehmen, 1997 wurde er Ehrenmitglied der Belgischen Gesellschaft für Neuraltherapie, 1998 Ehrenmitglied der Schweiz. Gesellschaft für ganzheitliche Zahnmedizin, 1998 Ehrenpräsident der Portugiesischen Neuraltherapiegesellschaft, 2002 Ehrenpräsident der Schweiz. Ärztegesellschaft für Erfahrungsmedizin und 2007 Ehrenmitglied der Deutschen Ärzte-Gesellschaft für Akupunktur und Neuraltherapie.

Wir danken ihm für seinen unermüdlichen, kämpferischen, kompromisslosen und uneigennützigen Einsatz für die Komplementärmedizin und im Besonderen für die Hingabe an seine Patienten, die er mit Liebe, Respekt und Sorgfalt betreute.

Andreas Beck hinterlässt eine grosse Lücke. Wir haben in ihm ein grosses Vorbild, einen Meister und Lehrer verloren.

Dr. med. dent. Marie-Anne Stettbacher und die Freunde von Andreas 